\title{
Editorials
}

\section{Quality assuring GPs and their practices}

The greatest driver for quality and protection of patients has always been doctors' desire to live up to the expectations of themselves, their colleagues, and their patients. This internal responsibility is at work in every clinical encounter. It is particularly significant in general practice where most of our clinical work is in one-toone consultations.

Yet inevitably we all at times fall short of our own expectations and those of our colleagues and patients. Mostly these lapses are temporary and forgivable. For the past 154 years, the General Medical Council (GMC) has been a regulator of the more egregious deviations in our behaviour; and in the past three decades it has also been concerned about our health and our competency as doctors. ${ }^{1}$

A third traditional accountability for doctors has been to wider society. This includes accountability through legislation concerning everything from prescribing to health and safety; in the courts through litigation and coroners; and to the NHS or other employers through contracts and complaints processes.

\section{FURTHER QUALITY MARKERS}

GPs have, additionally, sought voluntary markers of merit and quality. Prior to it becoming compulsory in 2007, the MRCGP examination was taken by the majority of young doctors wishing to enter general practice. Later in their careers, many wish to be recognised as a trainer and to acquire FRCGP. Fellowship by Assessment of the Royal College of General Practitioners (RCGP) was, from 1989 to 2007, a voluntary objective marker of good practice. ${ }^{2}$

Since 2005, every NHS GP has been expected to experience an annual appraisal with a trained, experienced colleague. While primarily intended to encourage personal development - formative in the jargon there has always been a clinical governance, summative, aspect in which concerns could be identified and addressed.

Practices, too, have undergone quality markers. While the Quality and Outcomes Framework focuses on a limited range of clinical performance indicators, ${ }^{3}$ recognition as a training practice, Quality Practice Award ${ }_{1}^{4}$ and practice accreditation ${ }^{5}$ are used by some to recognise the hard work involved in setting up and maintaining an eminent practice. In a review of practice accreditation in this issue of the BJGP, Helen Lester and her colleagues review general practice in Europe. ${ }^{6}$ It is clear that where practice accreditation is voluntary it remains, as in the UK, a minority activity.

It might be thought that this degree of accountability, compulsory and voluntary, would be sufficient for any profession. Yet this coming winter we expect to see the launch of revalidation - after more than a decade of gestation. Is this yet another layer of intrusive accountability designed to shackle doctors by creating a 'police state" in medicine? The answer will depend, of course, on your viewpoint.

\section{REVALIDATION}

All our existing compulsory external accountabilities are reactive - they cut in when things have gone wrong. The public, politicians, employers, and our medical leaders have recognised that proactive assurance is required if doctors, including GPs, are to retain their position of trust. The idea that a doctor practises for, say, three and a half decades between their specialist qualification, in our case the MRCGP, and retirement, with no way-station, seems incredible to many people.

If we are to have periodic renewal of our licence to practise (revalidation) then what information might persuade the GMC that we continue to be up to date and fit to practise? With one important exception, it is information that we in general practice already collect: successful completion of annual appraisals, continuing professional development activity, clinical audit, significant event auditing, and commentary on complaints. ${ }^{8}$

The 'new' area for some GPs is patient and colleague surveys, also referred to as multisource feedback. Not so long ago all of us did patient surveys but in recent years these have been replaced by NHS surveys which concentrate on access and services, not on us as doctors. For revalidation, we are again being expected to survey consulting patients at least once in every 5 years.

Colleague surveys have become embedded in vocational training and are becoming more common in non-training practices. In essence, a doctor identifies up to 20 clinical and non-clinical co-workers (the number varies between providers) to complete a questionnaire and comment on their strengths and weaknesses; again at least once in every 5 years. The resulting scores and comments are fed back to the doctor with comparative statistics for similar types of doctor.

\section{THE VALUE OF MULTISOURCE FEEDBACK}

Is this a useful exercise? Also in this issue Jacqueline Hill and colleagues interviewed 12 GPs who had undertaken both patient and colleague feedback and their 12 appraisers. ${ }^{9}$ While there was general agreement that such surveys are useful for formative development, doubts were expressed as to their value for a summative hurdle such as revalidation.

The counter-argument is as follows. Revalidation is not a once in 5 years passfail test but a continuous process in which there is periodic confirmation of the doctor's licence. None of the supporting information for revalidation is suitable, on its own, as a pass-fail test. What the supporting information, alongside annual appraisal and clinical governance systems, is designed to offer is insight into the behaviour and attributes of the doctor.

A safe, effective doctor is continuously reflecting and learning, striving for improvement, and using colleagues and patients as a reference point to understand how and where they should refine their practice. Colleague and patient surveys are therefore one way to gather insight for reflection, and to inform a doctor's personal development plan. The distinction between summative and formative information may,

\section{"The public, politicians, employers, and our medical leaders have recognised that proactive assurance is required if doctors, including GPS, are to retain their position of trust.}


"A safe effective doctor is continuously reflecting and

learning, striving for improvement, and using colleagues and patients as a reference point to understand how and where they should refine their practice."

therefore, not be as important as it first appears.

\section{WHAT NEXT?}

Once revalidation is bedded in, what might we expect then? There are no new regulatory initiatives on the horizon. So I expect that energies will be directed at refining the supporting information and the processes around revalidation, to ensure that they are minimally intrusive for the vast majority of good doctors and maximally effective at identifying those who give cause for concern.

We already know that, with some exceptions, GPs offer a level of care of which we can be extremely proud. Revalidation is intended to address those exceptions while assuring patients that whenever they access health care their doctor is regularly reviewed and is fit to practise. Such an outcome can and should be measured. It is imperative that, like all quality assurance interventions, revalidation is evaluated thoroughly. If revalidation can be shown to achieve its objectives then the wait and hassle will have been justified.

\section{Mike Pringle,}

Emeritus Professor Of General Practice, University of Nottingham, Nottinghamshire.

\section{Competing interests}

The author is the clinical lead for revalidation in the RCGP.

\section{Provenance}

Commissioned; not externally peer reviewed.

DOI: 10.3399/bjgp12X636281

\section{ADDRESS FOR CORRESPONDENCE}

\section{Mike Pringle}

Slacks Farmhouse, Low Street, Besthorpe, Newark, Notts, NG23 7HJ.

\section{E-mail: mikepringledabtinternet.com}

\section{REFERENCES}

. Irvine D. The doctor's tale: professionalism and public trust. Oxford: Radcliffe Press, 2003

2. Pringle M (ed.). Fellowship by assessment. Occasional paper 50, 2nd edn. London: Royal College of General Practitioners, 1995.

3. Mangin D, Toop L. The Quality and Outcomes Framework: what have you done to yourselves? Br J Gen Pract 2007; 57(539): 435-437.

4. Royal College of General Practitioners. Quality practice awards.

http://www.rcgp.org.uk/professional developme nt/team_quality/qpa.aspx laccessed $13 \mathrm{Apr}$ 2012).

5. Royal College of General Practitioners. Practice accreditation.

http://www.rcgp.org.uk/professional_developme nt/team_quality/practice_accreditation.aspx (accessed 13 Apr 2012).

6. Lester H, Eriksson T, Dijkstra E, et al. Practice accreditation: the European perspective. Br J Gen Pract 2012; DOI: 10.3399/bjgp12X641627.

7. Royal College of General Practitioners. Guide to revalidation for general practitioners. London: RCGP, 2012.

8. General Medical Council. Supporting information for appraisal and revalidation. London: GMC, 2011.

9. Hill JJ, Asprey A, Richards SH, Campbell JL. Multisource feedback questionnaires in appraisal and for revalidation: a qualitative study in UK general practice. Br J Gen Pract 2012; DOI: 10.3399/bjgp12X641429. 